\title{
Gestational diabetes mellitus is associated with antenatal hypercoagulability and secondary hyperfibrinolysis: a case control study of Chinese women
}

\author{
Yan Liu \\ Jiangsu Province Academy of Traditional Chinese Medicine \\ Xiaofang Sun \\ Yangzhou University Medical Academy \\ Junxian Tao \\ Yangzhou University Medical Academy \\ Bin Song \\ Yangzhou University Medical Academy \\ Wei Wu \\ Yangzhou University Medical Academy \\ Ying Li \\ Yangzhou University Medical Academy \\ Xing Sun \\ Yangzhou University Medical Academy \\ Dan Lu \\ Yangzhou University Medical Academy \\ Danmo Zhu \\ Yangzhou University Medical Academy \\ Chao Liu ( $\square$ liuchao@njucm.edu.cn ) \\ Nanjing University of Chinese Medicine https://orcid.org/0000-0003-0159-2952 \\ Ji Cui \\ Nanjing Maternity and Child Health Care Hospital
}

Research article

Keywords: gestational diabetes mellitus; hypercoagulability; secondary hyperfibrinolysis; thromboelastography;

Posted Date: October 30th, 2019 
DOI: https://doi.org/10.21203/rs.2.14831/v2

License: (c) (1) This work is licensed under a Creative Commons Attribution 4.0 International License. Read Full License

Version of Record: A version of this preprint was published at The Journal of Maternal-Fetal \& Neonatal Medicine on September 14th, 2020. See the published version at https://doi.org/10.1080/14767058.2020.1818202. 


\section{Abstract}

Background: To determine the relationship between gestational diabetes mellitus (GDM) and coagulation/fibrinolysis abnormality in antenatal Chinese women. Methods: Case control study. Fifty women had GDM and 132 did not (the NGDM group) grouping by the International Association of Diabetes and Pregnancy Study Groups (IADPSG) criteria. Maternal plasma biochemistry and previous medical history were collected from perinatal health records. Antenatal coagulation/fibrinolysis activity(CFA) parameters was assessed using thromboelastography and routine CFA parameters respectively. Univariate and multiple regression analyses were used to evaluate the associations between GDM and CFA parameters. Results: The women with GDM were significantly older than those without GDM (30.3 vs. 28.6 years, $P=0.012$ ). Compared with the NGDM group, the GDM group had a significantly higher prevalence of cesarean delivery $(56.0 \%$ vs. $37.9 \%, P=0.027)$ and higher values of fibrinogen (FIB) (4.7vs. $4.3 \mathrm{~g} / \mathrm{L} P=0.001$ ), activated partial thromboplastin time (APTT) (30.9 vs. 29.5 seconds $\mathrm{P}=0.010)$. There were no significant differences in the prevalence of maternal thrombotic events or neonatal events.GDM was significantly associated with higher APTT ( $\beta 1.41$ seconds, $95 \% \mathrm{Cl} 0.29-2.53$ ), FIB ( $\beta 0.38 \mathrm{~g} / \mathrm{L}, 95 \% \mathrm{Cl} 0.14-0.61)$, and percentage reduction in clot lysis after $30 \mathrm{~min}(\mathrm{LY} 30)(\beta 1.14 \%, 95 \%$ $\mathrm{Cl} 0.15-2.13)$ after adjustment for potential confounding factors. Conclusions: GDM is significantly associated with hypercoagulability and secondary hyperfibrinolysis in these antenatal Chinese women.

\section{Background}

Coagulation/fibrinolysis activity (CFA) represents a dynamic balance that is of vital importance to safe childbirth. Coagulability gradually increases from the first to third trimesters ${ }^{[1]}$ in pregnant women, becoming higher than in normal women ${ }^{[2]}$. Consistent with this, late pregnancy is characterized not only by changes in hormone secretion and liver metabolism, but higher coagulation indices ${ }^{[3]}$. Moreover, this hypercoagulability during pregnancy is aggravated in the presence of diabetes ${ }^{[4,5]}$. Excessive hypercoagulability is associated with adverse pregnancy outcomes, including stroke and deep venous thrombosis (DVT) of the lower extremities ${ }^{[6]}$. However, neither a nationwide study conducted in Denmark $^{[7]}$, nor another conducted in the Arabian Gulf ${ }^{[8]}$, identified GDM as a risk factor for stroke or DVT. Therefore, we hypothesized that secondary hyperfibrinolysis might coexist with, and gradually worsen, hypercoagulability in GDM.

Many methods have been used to assess CFA. Thromboelastography (TEG) is a relatively new technique that evaluates whole-blood hemostatic properties in real time, and has been shown to be a reliable method of urgently assessing CFA in pregnant women ${ }^{[9]}$. In addition, fibrinogen (FIB), activated partial thromboplastin time (APTT), prothrombin time (PT), international normalized ratio of prothrombin time (PT-INR), and D-Dimer (DD) are conventionally used to assess CFA. In view of the changes in CFA during late pregnancy, we speculated that there might be differences in a number of these parameters between women with GDM and normal pregnant women. However, the results of platelet activation, fibrinolytic activity, and conventional assays of CFA have rarely been compared in women with GDM ${ }^{[10]}$, and there 
has been no assessment of the relationship between GDM and CFA, assessed using TEG, in pregnant Chinese women. Therefore, in this study, we aimed to evaluate the relationship between GDM and measures of CFA, after adjustment for potential confounding factors.

\section{Methods}

\subsection{Study design and study population}

The study was a case control study. All procedures performed in the study involving the human participants were in accordance with the Declaration of Helsinki and was approved by the Ethics Committee of Clinical Medical College, Yangzhou University, China (serial number: 2019KY-067). During the analysis, the data were anonymized, and therefore the requirement for informed consent was waived. To avoid recruitment bias, we collected consecutive data from all pregnant women awaiting delivery, but not yet in labor, in the Obstetrics department of our hospital from 23 October to 23 November 2018. After the exclusion of 18 individuals for the reasons given below, 182 women were included in the analysis, who were classified as having GDM or not having GDM (the GDM group and the NGDM group).

GDM was diagnosed according to the IADPSG criteria ${ }^{[11]}$ : a 75-g 2-hour oral glucose tolerance test (OGTT) was performed in the 24th-28th week of gestation in women who had not previously been diagnosed with overt diabetes. A diagnosis of GDM was made when their fasting plasma glucose (FPG) was $\geq 92 \mathrm{mg} / \mathrm{dl}$ or $5.1 \mathrm{mmol} / \mathrm{l}$, their 1 -h plasma glucose was $\geq 180 \mathrm{mg} / \mathrm{dl}$ or $10.0 \mathrm{mmol} / \mathrm{l}$, or their $2-\mathrm{h}$ plasma glucose was $\geq 153 \mathrm{mg} / \mathrm{dl}$ or $8.5 \mathrm{mmol} / \mathrm{l}$.

The exclusion criteria were: a previous history of diabetes or GDM; a history of smoking; serious liver dysfunction (a prior diagnosis of cirrhosis, hepatitis, and/or known liver function test abnormalities); renal dysfunction (a prior diagnosis of acute kidney injury and/or chronic kidney disease); endocrine disorders (acromegaly, Cushing's syndrome); use of medications with known effects on CFA (such as aspirin, heparin, or enoxaparin); antiphospholipid syndrome; systemic lupus erythematosus or dermatomyositis; infectious disease (e.g., HIV); insulin or other anti-diabetic drug use.

Two hundred women who had never been smokers were included, 18 of whom were excluded because of severe liver disease (three), diabetes mellitus diagnosed before pregnancy (eleven), receive heparin treatment (two), and thrombocytopenia (two). Thus, 182 individuals remained for analysis (a flow chart is presented in Figure 1).

\subsection{Materials and methods}

Baseline information, including maternal weight before pregnancy, weight gain during pregnancy, and previous medical history, were collected from the patients' health records. Before delivery, the participants underwent a CFA assessment, which comprised the measurement of conventional CFA parameters (FIB, 
PT, APTT, PT-INR, and DD) and TEG. Venous blood was collected in the morning, on an empty stomach, and anti-coagulated with $0.38 \%$ sodium citrate. The blood was then centrifuged at $1500 \mathrm{~g}$ ( $2500 \mathrm{rpm}$ ) for 20 min to prepare plasma for APTT, PT, TT, FIB, and DD analysis, which was performed using a Stago STAR-R analyzer (Diagnostica STAGO, France). The remaining blood was placed into EDTA tubes for platelet counting using a Huma-Count hematology analyzer (Human GmbH, Germany).

TEG was performed using TEG-5000 Hemostasis analyzers (Haemonetics Corp, Braintree, MA) according to the manufacturer's guidelines ${ }^{[12-14]}$, by two certified laboratory technicians. The TEG-5000 machines underwent quality control assessments every 8 hours. The parameters measured were R (sec); K (sec); aangle; MA (mm) and LY30 (\%) (Figure 2). R represents "reaction time", an indicator of clotting time, and is the time to initial fibrin formation (to $2 \mathrm{~mm}$ amplitude). K represents "kinetic time", an indicator of clot kinetics, and is the speed at which specific clot strength is reached (period for amplitude to increase from 2 to $20 \mathrm{~mm}$ ). The a-angle is a measure of clot kinetics, indicative of the rate of fibrin accumulation and cross-linking. MA represents "maximum amplitude", an indicator of clot strength. LY30 is the percentage reduction in amplitude 30 min post-MA, which is a measure of the degree of fibrinolysis.

\subsection{Statistical analysis}

No multiple imputation was performed because $<5 \%$ of the data was missing.

The procedure of statistical analysis included three steps. Firstly, baseline characteristics of participants were presented based on the following principles (cases were categorized into GDM and NGDM): (1) continuous variable was expressed as mean \pm standard deviation (normal distribution) or medium (interquartile range) (Skewed distribution).Categorical variables were expressed as a frequency or a percentage. (2) We used chi-squared tests or Fisher exact tests as appropriate for comparison of categorical data between the two groups. For continuous data, if the data were normally distributed, the comparisons of measurement data between groups were performed by $t$ test. When the data showed skewed distribution, comparisons were performed by nonparametric Kruskal Wallis rank tests. (3) For the comparisons of bleeding volume, we used stratification analysis based on the mode of delivery (vaginal or caesarean). Secondly, a univariate linear regression model was employed to evaluate the associations between different variables and CFA parameters. Thirdly, based on the recommendation of the STROBE statement ${ }^{[15]}$, unadjusted and adjusted regression models were simultaneously shown to assess the relationships between GDM and CFA parameters. The covariables, when added to this model, changed the matched regression coefficients by at least $10 \%$ and were adjusted as confounders ${ }^{[16]}$. Adjusted covariables included maternal age, platelet, ALT, ALP, urea nitrogen, and previous history of abortion.

All the analyses were performed using EmpowerStats (http://www.empowerstats.com, X\&Y Solutions, Inc, Boston, MA). $P<0.05$ (two-sided) was considered to represent statistical significance.

\section{Results}




\subsection{Baseline characteristics of selected participants}

The participants comprised 50 with GDM, accounting for $27 \%$ of the study sample. The baseline information of each group are shown in Table 1, which include sociodemographic characteristics, previous medical history, biochemistry, sociodemographic characteristics of the baby, maternal events, and neonatal events. The mean age of the participants was $29.1 \pm 4.1$ years and their mean maternal body mass index (BMI) before delivery was $27.2 \pm 3.4 \mathrm{~kg} / \mathrm{m}^{2}$. The women with GDM were significantly older than those without GDM (30.3vs. 28.6 years, $P=0.012)$. The weight of the women with GDM before pregnancy was greater than that of the NGDM group $(61.8 \mathrm{vs} .56 .0 \mathrm{~kg}, P=0.000)$, whereas the maternal weight gain during pregnancy was less in the GDM than in the NGDM group $(11.7 \mathrm{vs} .14 .2 \mathrm{~kg}, P=0.001)$. GDM had shorter pregnancy duration (271.3 vs. 274.7 days, $P=0.013$ ) and higher values of serum total bilirubin (STB) $(6.5 \mathrm{vs}$. $6.0 \mu \mathrm{mol} / \mathrm{L}, P=0.013)$, alkaline phosphatas (ALP) $(175.8 \mathrm{vs} .158 .2 \mu \mathrm{mol} / \mathrm{L}, P=0.028)$, fasting plasma glucose (FPG) $(4.8 \mathrm{vs} .4 .2 \mathrm{mmol} / \mathrm{L}, P<0.001)$ than NGDM. The prevalence of caesarean delivery was higher in the GDM group $(56.0 \%)$ than that in the NGDM group $(37.9 \%)(P=0.027)$. For CFA parameters, only FIB $(4.7 \pm 0.8$ vs. $4.3 \pm 0.7 \mathrm{~g} / \mathrm{l}, P=0.001)$ and APTT $(30.9 \pm 3.0$ vs. $29.5 \pm 3.3$ seconds, $P=0.010$ ) were significantly higher in the GDM than those in the NGDM group. Other parameters including PT, TT, PT-INR, and DD didn't show the significant differences between the two groups, as were the TEG parameters, including LY30.

\subsection{Univariate analysis}

The results of the univariate analyses were shown in Table 2. GDM was shown to be significantly positively associated with LY30, FIB, and APTT. Furthermore, Platelet, ALT, ALP, GGT, and Maternal FPG significantly positively correlated with FIB. Maternal weight gain during pregnancy, a previous history of abortion, and a previous history of full-term birth were negatively associated with FIB. Finally, ALT significantly positively correlated with LY30.

2.3 Analysis of the multiple regression equations for the relationships between FIB,APTT,LY3O and GDM

We constructed three models to analyze the independent effects of GDM on FIB,APTT,LY30, after adjustment for potential confounding factors. The effect values $(\beta)$ and $95 \%$ confidence intervals (Cls) of the two models are shown in Table 3. In the unadjusted model, GDM was positively associated with APTT ( $\beta 1.40,95 \% \mathrm{Cl} 0.34-2.46)$, FIB ( $\beta$ 0.39, 95\% Cl 0.16-0.63), and LY30 ( $\beta 1.30,95 \% \mathrm{Cl} 0.35-2.24)$. Finally, after adjustment for Prenatal maternal age, Plasma urea nitrogen, ALT, Platelet, Previous history of abortion and ALP (Table 1), GDM was still independently associated with APTT ( $\beta 1.41,95 \% \mathrm{Cl} 0.29-$ 2.53), FIB ( $\beta 0.38,95 \% \mathrm{Cl} 0.14-0.61)$, and LY30 ( $\beta 1.14,95 \% \mathrm{Cl} 0.15-2.13)$.

\section{Discussion}


In this case control study, both the conventional CFA measures FIB and APTT, and the newer measure indicator LY30, were found to be significantly associated with GDM, and in the fully-adjusted regression model, these associations remained stable. In women with GDM, APTT was $1.41 \mathrm{sec}$ longer $(\beta 1.41,95 \%$ $\mathrm{Cl} 0.29-2.53)$, FIB was $0.38 \mathrm{~g} / \mathrm{L}$ higher $(\beta 0.38,95 \% \mathrm{Cl} 0.14-0.61)$, and $\mathrm{LY} 30$ was $1.14 \%$ higher ( $\beta 1.14$, $95 \% \mathrm{Cl} 0.15-2.13)$, which is indicative of both hypercoagulability and secondary hyperfibrinolysis in this group of Chinese women with GDM.

Maintenance of a balance between coagulation and fibrinolysis is of great importance for the perinatal safety of both mothers and infants ${ }^{[17]}$. A physiologic hypercoagulable state has been demonstrated during pregnancy and the peripartum period ${ }^{[17,18]}$, which helps to protect women from excessive bleeding during childbirth. Nevertheless, in developed nations, the leading cause of maternal death is thromboembolic disease ${ }^{[19-21]}$. Thrombotic events during pregnancy, including maternal DVT(deep venous thrombosis) and pregnancy-related cerebral venous sinus thrombosis, are responsible for increasing levels of maternal mortality worldwide ${ }^{[22,23]}$. Previous studies have shown that this hypercoagulability is exacerbated in pregnant women with $\mathrm{GDM}^{[4,24,25]}$ and that there is a significantly higher frequency of DVT in pregnant women with type 1 diabetes mellitus ${ }^{[26]}$. However, in a nationwide study conducted in Denmark, an unadjusted model showed a higher risk of thrombosis in patients with GDM, but in a model adjusted for confounding factors this association disappeared ${ }^{[7]}$. In previous studies $^{[7,27]}$ and our study, no significant differences were identified in the frequency of maternal thrombotic events in GDM group compared with NGDM group, which seems to be inconsistent with the hypercoagulability identified.

The balance between coagulation and fibrinolysis determines whether hemorrhage, thrombosis, or neither occurs during the perinatal period. FIB is one of the conventional measures of coagulability during the perinatal period, as well as being a biomarker of inflammation, and is a complex glycoprotein synthesized by hepatocytes ${ }^{[28]}$. FIB increases during normal pregnancies, but also in pregnancy-related complications such as $\operatorname{GDM}^{[29,30]}$, reaching significantly higher values in patients with GDM than those in healthy pregnant women ${ }^{[24,30]}$. In the present study, FIB was also higher in GDM patients than that in the NGDM group, confirming a tendency towards hypercoagulability in the former.

The shortening of APTT in type 2 diabetic patients has been described as indicating a high risk of a hypercoagulable state ${ }^{[31]}$. It has also been shown that the increase in fibrinogen and the reduction in fibrinolytic activity in GDM are more similar to the changes present in type 2 than in type 1 diabetic patients ${ }^{[32]}$, and it is thought that a shorter APTT is a marker of venous thromboembolism risk ${ }^{[33,34]}$. Furthermore, PT and APTT, measured between the 20th and 24th gestational weeks, were significantly lower in patients with GDM than in healthy people ${ }^{[29]}$. In another study, the mean APTTs of non-diabetic, treated, and untreated type 2 diabetic patients were $32.8 \pm 4.12 \mathrm{sec}, 34.4 \pm 5.3 \mathrm{sec}$, and $25.4 \pm 8.5 \mathrm{sec}$, respectively, which showed that APTT was lower in diabetic patients and that this defect was normalized by diabetes treatment ${ }^{[31]}$. This might help to explain the significantly higher APTT in GDM patients identified in the present study. The prenatal maternal FPG $(4.8 \pm 1.2 \mathrm{mmol} / \mathrm{I})$ and $\mathrm{HbA} 1 \mathrm{c}(6.5 \pm 0.7 \%)$ values 
in the GDM group show that glucose levels were well controlled in the present study. In addition, the significantly lower maternal weight gain during pregnancy in the GDM group is indicative of good weight control in our recruited subjects. Finally, the characteristic increases in FIB and APTT, indicating hypercoagulability and secondary hyperfibrinolysis, might help to partially explain why there were no significant differences in the prevalence of some adverse maternal events, such as maternal thrombosis, between these "healthy" GDM women and NGDM women.

Fibrinolytic activity is lower during normal pregnancies and systemic fibrinolysis returns rapidly to normal after delivery, according to previous studies ${ }^{[35,36]}$. After delivery, both the coagulatory and fibrinolytic systems of pregnant women are activated for at least 2 weeks ${ }^{[37]}$. However, few studies have focused on the fibrinolytic activity in GDM. Recently, TEG has been used to monitor the CFA of pregnant women in real time, to study the human CFA process and the sequence of events involved ${ }^{[38]}$. The TEG parameters measured in the present study have further indicated the secondary hyperfibrinolysis. There were no significant differences in TEG.R, TEG.K, TEG.MA, LY30, or a-angle between the GDM and NGDM groups, which is consistent with the findings of a previous report that showed no significant differences in thromboelastographic parameters between 50 GDM patients and a control group(75 women of normal pregnancies at the same period) ${ }^{[39]}$. However, after adjustment for potential confounders, GDM was significantly associated with higher value of LY30, which further suggested the existence of secondary hyperfibrinolysis in these pregnant women with GDM. The coexistence of hypercoagulability and secondary hyperfibrinolysis might help to partially explain why there was no significant increase in the number of thrombotic events in these GDM patients. However, the mechanism involved and its impact on the children of these patients requires further study.

The clinical value of this study is two-fold. Firstly, we have shown significant associations between GDM and higher APTT, LY30, and FIB. Secondly, CFA of the pregnant women was assessed by using both conventional CFA measures and TEG at the same time point and the results were consistent. The findings of this study might be helpful in guiding further research regarding biomarkers that could sensitively predict the risk of thrombotic events in GDM patients. Additionally, our study was a single-center study, indicating that the study population was more homogeneous. The maternity center is located in a small city in China that has relatively few population migrations, and most of the participants in this study were local residents. As previously reported ${ }^{[34]}$, the influence of ethnicity on coagulation might exist that could be excluded in our study.

However, this study still had a number of limitations. Firstly, because the data were collected in a single local population, the conclusion should be confirmed by further research and multi-center study.

Secondly, we excluded pregnant women that had undergone heparin treatment and that had a history of other diseases, such as severe liver disease, which might have affected CFA. Thus, the conclusions of this study do not apply to pregnant women with these kinds of diseases. Thirdly, in our study, IADPSG criteria was adopted which was recently widely used in China ${ }^{[40]}$. However, it was reported recently that an increase in the prevalence of GDM when the IADPSG 1-step approach was adopted without an increase 
of maternal or neonatal outcomes compared with ACOG 2-step strategy ${ }^{[41]}$. So grouping by IADPSG criteria might result in diagnosing more GDM patients and reducing sensitivity of monitoring. Finally, most obstetricians in our hospital do not measure serum lipid concentrations just before delivery; therefore, we could not analyze the influence of serum lipid levels on the CFA function of women with GDM. This deficiency should be considered in future studies' design.

\section{Conclusion}

In this case control study, women with GDM demonstrated significant hypercoagulability and secondary hyperfibrinolysis, shown by their significantly higher FIB, APTT, and LY30 values after adjustment for potential confounding factors. This concomitant hypercoagulability and secondary hyperfibrinolysis in these antenatal GDM patients might help to reveal that antenatal GDM patients still had abnormalities in coagulation and fibrinolysis even without significant increase of thrombotic events.

\section{Abbreviations}

CFA: Coagulation/fibrinolysis activity; GDM: gestational diabetes mellitus; DVT: deep venous thrombosis ; TEG: Thromboelastography ; FIB: fibrinogen; APTT: activated partial thromboplastin time; PT:

prothrombin time; PT-INR: international normalized ratio of prothrombin time; DD:D-Dimer; OGTT: oral glucose tolerance test; R:reaction time; K:kinetic time; MA: maximum amplitude; LY30: percentage reduction in amplitude 30 min post-MA; BMI $₫$ Body mass index; SBP: systolic blood pressure; DBP: diastolic blood pressure; RBC: blood erythrocytes count; WBC: blood leukocyte Count; NE: neutrophile granulocyte; DBIL: direct bilirubin; STB: serum total bilirubin; IBIL: indirect bilirubin; AST囚aspartate aminotransferarase; ALT: alanine aminotransferarase; LDH: lactate dehydrogenase; ALP: alkaline phosphatase; $\gamma$-GGT: $\gamma$-glutamyl transpeptadase; HbA1c: glycated haemoglobin; UA: plasma uric acid; Cls $₫$ confidence intervals $\otimes \mathrm{FPG}$ :fasting plasma glucose.

\section{Declarations}

Ethics approval and consent to participate

All procedures performed in the study involving the human participants were in accordance with the Declaration of Helsinki and was approved by the Ethics Committee of Clinical Medical College, Yangzhou University, China (serial number: 2019KY-067). During the analysis, the data were anonymized, and therefore the requirement for informed consent was waived by the local ethics committee with no impact on health outcome.

Consent for publication

During the analysis, the data were anonymized, and therefore the requirement for informed consent was waived by the local ethics committee with no impact on health outcome. 
Availability of data and material

The datasets used and/or analyzed during the current study are available from the corresponding author on reasonable request.

Competing interests

All authors declare that they have no competing interests.

Funding

The development of the analytic methods and software used in this work was supported by the Foundation of Jiangsu Subei People's Hospital (fcjs201834). And writing the manuscript was supported in part by the TCM Leading Talents Training Project of Jiangsu Province (SLJ0209)

Authors' contributions

$\mathrm{YL}, \mathrm{XFS}$, JXT, CL and JC were responsible for conception, design of the study, acquisition, analysis and interpretation of data. WW, XS were responsible for the test and quality control of CFA assessment. DL and DMZ were responsible for discrimination of obstetric diseases. YL, BS,YL drafted the article and revised contents. All authors have read and approved the final version of the manuscript.

Acknowledgements

The authors thank all the staff members in our institution, and especially Mr. Liu Shunshun, Mr. Sun Guoping, and Miss. Sun Lemeng, the Empower team. We also thank Mrs. Tang Shao Hua, from Yangzhou university and Mark Cleasby, PhD, from Liwen Bianji, Edanz Group China (www.liwenbianji.cn/ac), for editing the English text of a draft of this manuscript.

\section{References}

[1] Ibeh N, Okocha CE, Aneke CJ, Onah CE, Nwosu AO, Nkwazema KA. Normal pregnancy and coagulation profile: from the first through the third trimester. Nigerian journal of medicine : journal of the National Association of Resident Doctors of Nigeria. 2015;24(1): 54-7.PMID:25807675.

[2] Della Rocca G, Dogareschi T, Cecconet T, Buttera S, Spasiano A, Nadbath P, Angelini M, Galluzzo C, Marchesoni D. Coagulation assessment in normal pregnancy: thrombelastography with citrated non activated samples. Minerva anestesiologica.2012; 78(12): 1357-64. PMID:22858878.

[3] Gong JM, Shen Y, He YX. Reference Intervals of Routine Coagulation Assays During the Pregnancy and Puerperium Period. Journal of clinical laboratory analysis. 2016;30(6): 912-7.

[4] Teliga-Czajkowska J, Sienko J, Zareba-Szczudlik J, Malinowska-Polubiec A, Romejko-Wolniewicz E, Czajkowski K. Influence of Glycemic Control on Coagulation and Lipid Metabolism in Pregnancies 
Complicated by Prege stational and Gestational Diabetes Mellitus. Adv Exp Med Biol, 2019;1176:81-88.

[5] Liu B, Xu Y, Voss C, Qiu FH, Zhao MZ, Liu YD, Nie J, Wang ZL. Altered protein expression in gestational diabetes mellitus placentas provides insight into insulin resistance and coagulation/fibrinolysis pathways. PloS one. 2012; 7(9): e44701.

[6] Krikun G, Huang ST, Schatz F, Salafia C, Stocco C, Lockwood CJ. Thrombin activation of endometrial endothelial cells: a possible role in intrauterine growth restriction. Thrombosis and haemostasis.2007;97(2): 245-53.

[7] Ovesen PG, Jensen DM, Damm P, Rasmussen S, Kesmodel US. Maternal and neonatal outcomes in pregnancies complicated by gestational diabetes. a nation-wide study. The journal of maternal-fetal \& neonatal medicine : the official journal of the European Association of Perinatal Medicine, the Federation of Asia and Oceania Perinatal Societies. the International Society of Perinatal Obstet.2015:28(14): 17204.

[8] Alsayegh F, Al-Jassar W, Wani S, Tahlak M, Albahar A, Al Kharusi L, Al-Tamimi H, El-Taher F, Mahmood N, Al-Zakwani I. Venous Thromboembolism Risk and Adequacy of Prophylaxis in High Risk Pregnancy in the Arabian Gulf. Curr Vasc Pharmacol. 2016;14(4): 368-73.

[9] Jarmuzek P, Wielgos M, Bomba-Opon D. Placental pathologic changes in gestational diabetes mellitus. Neuro endocrinology letters.2015;36(2): 101-5.

[10] Liu BY, Jian YL, Zhong M, Yu YH, Wang Q, Zhang J. [Value of coagulation function and fibrinolytic system assessment in patients with gestational diabetes mellitus]. Nan Fang Yi Ke Da Xue Xue Bao.2007; 27(1): 35-7.

[11] American Diabetes A. 2. Classification and Diagnosis of Diabetes: Standards of Medical Care in Diabetes-2018. Diabetes care. 2018;41(Suppl 1): S13-s27.

[12] Antony KM, Mansouri R, Arndt M, Rocky Hui SK, Jariwala P, Mcmullen VM, Teruya J, Aagaard K. Establishing thromboelastography with platelet-function analyzer reference ranges and other measures in healthy term pregnant women. American journal of perinatology.2015;32(6): 545-54.

[13] Zahr Eldeen F, Roll GR, Derosas C, Rao R, Khan MS, Gunson BK, Hodson J, Mergental H, FerrazNeto BH, Isaac J, Muiesan P, Mirza DF, Iqbal A, Perera MT. Preoperative Thromboelastography as a Sensitive Tool Predicting Those at Risk of Developing Early Hep atic Artery Thrombosis After Adult Liver Transplantation. Transplantation.2016; 100(11): 2382-90.

[14] Brill JB, Badiee J, Zander AL, Wallace JD, Lewis PR, Sise MJ, Bansal V, Shackford SR. The rate of deep vein thrombosis doubles in trauma patients with hypercoagulable thromboelastography. J Trauma Acute Care Surg.2017; 83(3): 413-9. 
[15] Vandenbroucke JP, Von Elm E, Altman DG, Gotzsche PC, Mulrow CD, Pocock SJ, Poole C, Schlesselman JJ, Egger M. Strengthening the Reporting of Observational Studies in Epidemiology (STROBE): explanation and elaboration. PLoS Med.2007; 4(10): e297.

[16] Kernan WN, Viscoli CM, Brass LM, Broderick JP, Brott T, Feldmann E, Morgenstern LB, Wilterdink JL, Horwitz RI. Phenylpropanolamine and the risk of hemorrhagic stroke. N Engl J Med.2000;343(25): 1826-32.

[17] Sousa Gomes M, Guimaraes M, Montenegro N. Thrombolysis in pregnancy: a literature review. The journal of maternal-fetal \& neonatal medicine : the official journal of the European Association of Perinatal Medicine, the Federation of Asia and Oceania Perinatal Societies, the International Society of Perinatal Obstet. 2019; 32(14): 2418-28.

[18] Chandra S, Tripathi AK, Mishra S, Amzarul M, Vaish AK. Physiological changes in hematological parameters during pregnancy. Indian journal of hematology \& blood transfusion : an official journal of Indian Society of Hematology and Blood Transfusion.2012; 28(3): 144-6.

[19] Marik PE, Plante LA. Venous thromboembolic disease and pregnancy. N Engl J Med. 2008; 359(19): 2025-33.

[20] Edlow JA, Caplan LR, O'brien K, Tibbles CD. Diagnosis of acute neurological emergencies in pregnant and post-partum women. Lancet Neurol. 2013; 12(2): 175-85.

[21] Heit JA, Kobbervig CE, James AH, Petterson TM, Bailey KR, Melton LJ. Trends in the incidence of venous thromboembolism during pregnancy or postpartum: a 30-year population-based study. Ann Intern Med.2005; 143(10): 697-706.

[22] Liang ZW, Gao WL, Feng LM. Clinical characteristics and prognosis of cerebral venous thrombosis in Chinese women during pregnancy and puerperium. Scientific reports. 2017;7:43866.

[23] Devis P, Knuttinen MG. Deep venous thrombosis in pregnancy: incidence, pathogenesis and endovascular management. Cardiovasc Diagn Ther. 2017;7(Suppl 3): S309-s19.

[24] Abdel Gader AG, Khashoggi TY, Habib F, Awadallah SB. Haemostatic and cytokine changes in gestational diabetes mellitus. Gynecological endocrinology : the official journal of the International Society of Gynecological Endocrinology. 2011;27(5): 356-60.

[25] Gumus, li, Kargili A, Karakurt F, Kasapoglu B, Derbent A, Kaygusuz I, Koca C, Sevgili S. Levels of thrombin activatable fibrinolysis inhibitor in gestational diabetes mellitus. Gynecological endocrinology : the official journal of the International Society of Gynecological Endocrinology.2013;29(4): 327-30.

[26] Bleau N, Patenaude V, Abenhaim HA. Risk of Venous Thromboembolic Events in Pregnant Patients With Autoimmune Diseases: A Population-Base d Study. Clin Appl Thromb Hemost.2016;22(3): 285-91. 
[27] Yang YY, Fang YH, Wang X, Zhang Y, Liu XJ, Yin ZZ. A retrospective cohort study of risk factors and pregnancy outcomes in 14,014 Chinese pregnant women. Medicine (Baltimore).2018;97(33): e11748.

[28] Ko GT, Yeung VT, Chan JC, Chow CC, Li JK, So WY, Tsang LW, Cockram CS. Plasma fibrinogen concentration in a Chinese population. Atherosclerosis. 1997;131(2): 211-7.

[29] Gorar S, Alioglu B, Ademoglu E, Uyar S, Bekdemir H, Candan Z, Saglam B, Koc G, Culha C, Aral Y. Is There a Tendency for Thrombosis in Gestational Diabetes Mellitus?.Journal of laboratory physicians.2016; 8(2): 101-5.

[30] Bellart J, Gilabert R, Fontcuberta J, Carreras E, Miralles RM, Cabero L. Coagulation and fibrinolysis parameters in normal pregnancy and in gestational diabetes. American journal of perinatology.1998;15(8): 479-86.

[31] Ambelu YA, Shiferaw MB, Abebe M, Enawgaw B. Prothrombin time, activated partial thromboplastin time and platelet counts of type II diabetes mellitus: a comparative study. J Diabetes Metab Disord. 2018;17(2): 117-21.

[32] Kvasnicka J, Bendl J, Zivn J, Umlaufov“" $\mathrm{A}$ A, Maslowsk“" $\mathrm{H}$ H. [Changes in hemostasis and fibrinolysis in gestational diabetes]. Cas Lek Cesk.1996;135(4): 106-10.

[33] Aboud MR, Ma DD. Increased incidence of venous thrombosis in patients with shortened activated partial thromboplastin times and low ratios for activated protein $\mathrm{C}$ resistance. Clin Lab Haematol. 2001; 23(6): 411-6.

[34] Weng LC, Cushman M, Pankow JS, Basu S, Boerwinkle E, Folsom AR, Tang W. A genetic association study of activated partial thromboplastin time in European Americans and African Americans: the ARIC Study. Hum Mol Genet. 2015; 24(8): 2401-8.

[35] Djelmis J, Ivanisevic M, Kurjak A, Mayer D. Hemostatic problems before, during and after delivery. J Perinat Med. 2001; 29(3): 241-6.

[36] Wright JG, Cooper P, Astedt B, Lecander I, Wilde JT, Preston FE, Greaves M. Fibrinolysis during normal human pregnancy: complex inter-relationships between plasma levels of tissue plasminogen activator and inhibitors and the euglobulin clot lysis time. Br J Haematol.1988;69(2): 253-8.

[37] Pelage JP, Fohlen A, Le Pennec V. [Role of arterial embolization in the management of postpartum hemorrhage]. J Gynecol Obstet Biol Reprod (Paris).2014;43(10): 1063-82.

[38] Meier J. A new application for thrombelastography in pregnant women at term. Minerva anestesiologica. 2012; 78(12): 1319-20.

[39] Wang W, Wang AM, Huang XQ, Jiang W, Jia XN. Thromboelastography in women with pathological pregnancies: a preliminary study. Chin Med Sci J. 2014;29(1): 63-4. 
[40] Zhang H, Dong H, Ren M, Liang Q, Shen X, Wang Q, Yu L, Lin H, Luo Q, Chen W, Knibbs LD, Jalaludin B, Wang Q, Huang C. Ambient air pollution exposure and gestational diabetes mellitus in Guangzhou, China: A prospective cohort study. Sci Total Environ. 2019; 699(134390.

[41] Ogunleye OK, Davidson KD, Gregg AR, Egerman RS. Perinatal outcomes after adopting 1- versus 2-step approach to diagnosing gestational diabetes. The journal of maternal-fetal \& neonatal medicine : the official journal of the European Association of Perinatal Medicine, the Federation of Asia and Oceania Perinatal Societies, the International Society of Perinatal Obstet.2017;30(2): 186-90.

\section{Tables}

Table 1 Baseline characteristics of selected participants 


\begin{tabular}{|c|c|c|c|}
\hline & $\begin{array}{l}\text { GDM group } \\
\mathrm{N}=50\end{array}$ & $\begin{array}{l}\text { NGDM group } \\
\mathrm{N}=132\end{array}$ & $\begin{array}{l}P \text { - } \\
\text { value }\end{array}$ \\
\hline Sociodemographic characteristics of gravidas & & & \\
\hline $\begin{array}{l}\text { Prenatal maternal age (years, mean } \pm \mathrm{sd}) \\
\text { Prenatal maternal } \mathrm{BMl}\left(\mathrm{kg} / \mathrm{m}^{2}, \text { mean } \pm \mathrm{sd}\right)\end{array}$ & $\begin{array}{l}30.3 \pm 4.4 \\
27.9 \pm 3.5\end{array}$ & $\begin{array}{l}28.6 \pm 3.9 \\
26.9 \pm 3.3\end{array}$ & $\begin{array}{l}0.012 \\
0.091\end{array}$ \\
\hline $\begin{array}{l}\text { Prenatal maternal weight }(\mathrm{kg} \text {, mean } \pm \mathrm{sd}) \\
\text { Maternal weight before pregnancy }(\mathrm{kg}, \text { mean } \pm \mathrm{sd})\end{array}$ & $\begin{array}{l}73.5 \pm 10.1 \\
61.8 \pm 9.5\end{array}$ & $\begin{array}{l}70.1 \pm 9.0 \\
56.0 \pm 8.3\end{array}$ & $\begin{array}{l}0.053 \\
0.000\end{array}$ \\
\hline $\begin{array}{l}\text { Maternal weight gain during pregnancy }\left(\mathrm{kg} / \mathrm{m}^{2}\right. \\
\text { mean } \pm \mathrm{sd})\end{array}$ & $11.7 \pm 4.7$ & $14.2 \pm 4.2$ & 0.001 \\
\hline $\begin{array}{l}\text { SBP }(m m H g, \text { mean } \pm s d) \\
\text { DBP }(m m H g, \text { mean } \pm \text { sd }) \\
\text { Actual days of preanancy (days, mean } \pm \text { sd })\end{array}$ & $\begin{array}{l}121.0 \pm 10.3 \\
80.4 \pm 8.2 \\
271.3+8.3\end{array}$ & $\begin{array}{l}122.5 \pm 11.1 \\
79.4+9.0 \\
274.7+110\end{array}$ & $\begin{array}{l}0.405 \\
0.693 \\
0.013\end{array}$ \\
\hline $\begin{array}{l}\text { Previous maternal history } \\
\text { Prol }\end{array}$ & & & \\
\hline $\begin{array}{l}\text { Thyroid disorder during pregnancy (n,\%) } \\
\text { Preecalmpsia and clampsia n,\%) } \\
\text { Previous history of full-term births times } \\
\text { Previous history of premature delivery } \\
\text { Previous history of abortion } \\
\text { Maternal biochemical indexes }\end{array}$ & $\begin{array}{l}7(14.0 \%) \\
1(2.0 \%) \\
26(52.0 \%) \\
0(0.0 \%) \\
23(46.0 \%)\end{array}$ & $\begin{array}{l}21(15.9 \%) \\
2(1.5 \%) \\
58(43.9 \%) \\
3(2.3 \%) \\
54(40.9 \%)\end{array}$ & $\begin{array}{l}0.931 \\
0.677 \\
0.330 \\
0.563 \\
0.535\end{array}$ \\
\hline $\operatorname{RBC}\left(\times 10^{9} / L\right.$, mean $\left.\pm \mathrm{sd}\right)$ & $4.1 \pm 0.6$ & $4.0 \pm 0.4$ & 0.115 \\
\hline $\begin{array}{l}\text { Hemoglobin }(\mathrm{g} / \mathrm{L}, \text { mean } \pm \mathrm{sd}) \\
\mathrm{WBC}\left(\times 10^{9} / \mathrm{L} \text {, mean } \pm \mathrm{sd}\right)\end{array}$ & $\begin{array}{l}124.7 \pm 12.3 \\
8.3 \pm 2.6\end{array}$ & $\begin{array}{l}120.5 \pm 13.4 \\
9.1 \pm 2.3\end{array}$ & $\begin{array}{l}0.052 \\
0.068\end{array}$ \\
\hline $\mathrm{NE}\left(\times 10^{9} / \mathrm{L}\right.$, mean $\left.\pm \mathrm{sd}\right)$ & $6.3 \pm 2.3$ & $6.8 \pm 2.1$ & 0.183 \\
\hline Platelet $\left(\times 10^{9} / \mathrm{L}\right.$, mean $\left.\pm \mathrm{sd}\right)$ & $180.5 \pm 42.8$ & $194.3 \pm 50.3$ & 0.207 \\
\hline $\begin{array}{l}\text { ALB }(\mathrm{g} / \mathrm{L}, \text { mean } \pm \mathrm{sd}) \\
\text { Plasma total protein }(\mathrm{g} / \mathrm{L}, \text { mean } \pm \mathrm{sd}) \\
\text { Plasma globulin }(\mathrm{g} / \mathrm{L}, \text { mean } \pm \mathrm{sd}) \\
\text { DBIL }(\mu \mathrm{mol} / \mathrm{L} \square \text { median }(\mathrm{Q} 1-\mathrm{Q} 3)) \\
\text { STB }(\mu \mathrm{mol} / \mathrm{L} \square \text { mean } \pm \mathrm{sd}) \\
\text { IBIL }(\mu \mathrm{mol} / \mathrm{L} \square \text { mean } \pm \mathrm{sd}) \\
\text { AST }(\mathrm{U} / \mathrm{L}, \text { mean } \pm \mathrm{sd}) \\
\text { ALT }(\mathrm{U} / \mathrm{L}, \text { median }(\mathrm{Q} 1-\mathrm{Q} 3)) \\
\mathrm{LDH}(\mathrm{U} / \mathrm{L}, \text { median }(\mathrm{Q} 1-\mathrm{Q} 3))\end{array}$ & $\begin{array}{l}35.5 \pm 3.3 \\
61.9 \pm 5.0 \\
26.4 \pm 3.7 \\
2.7(2.0-3.4) \\
8.4 \pm 5.2 \\
4.9 \pm 3.1 \\
22.9 \pm 16.9 \\
15.0(10.0-25.5) \\
192.0(161.5- \\
236.8)\end{array}$ & $\begin{array}{l}36.0 \pm 3.6 \\
63.1 \pm 5.9 \\
27.0 \pm 4.6 \\
2.2(1.7-3.2) \\
6.8 \pm 3.6 \\
4.3 \pm 3.0 \\
20.6 \pm 8.1 \\
12.5(9.0-20.2) \\
194.0(171.0- \\
220.2)\end{array}$ & $\begin{array}{l}0.362 \\
0.220 \\
0.567 \\
0.093 \\
0.012 \\
0.113 \\
0.209 \\
0.168 \\
0.799\end{array}$ \\
\hline $\begin{array}{l}\text { ALP(U/L, mean } \pm \text { sd) } \\
\text { GGT }(\mathrm{U} / \mathrm{L}, \text { median }(\mathrm{Q} 1-\mathrm{Q} 3)) \\
\mathrm{FPG}(\mathrm{mmol} / \mathrm{L}, \text { mean } \pm \mathrm{sd})\end{array}$ & $\begin{array}{l}175.8 \pm 50.2 \\
11.0(8.0-22.0) \\
4.8 \pm 1.2\end{array}$ & $\begin{array}{l}158.2 \pm 46.7 \\
11.5(8.0-18.0) \\
4.2 \pm 0.7\end{array}$ & $\begin{array}{l}0.028 \\
0.610 \\
0.001\end{array}$ \\
\hline 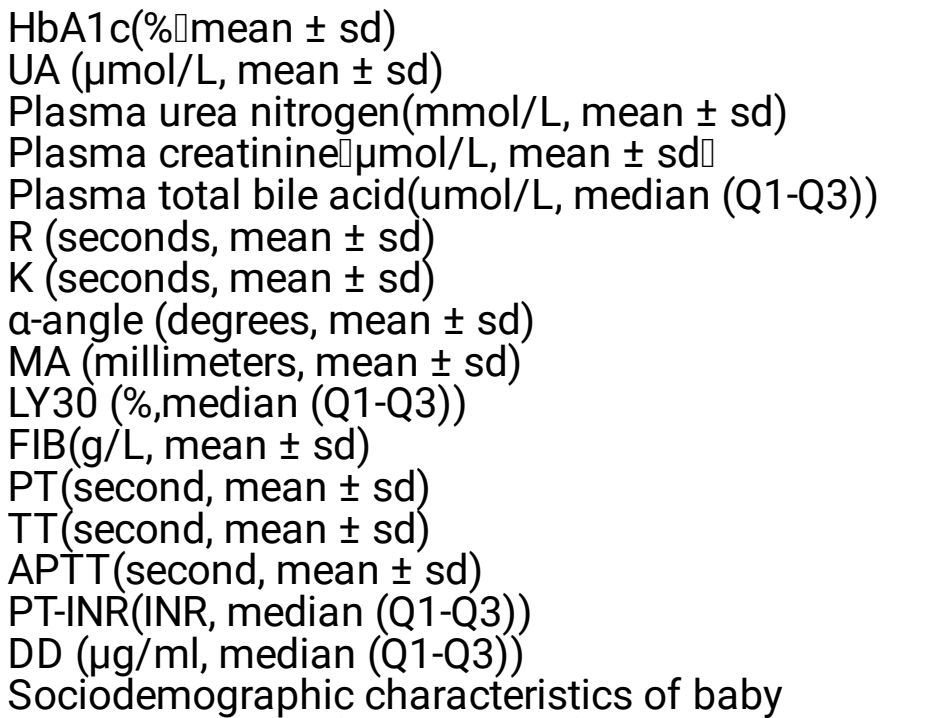 & $\begin{array}{l}6.5 \pm 0.7 \\
300.8 \pm 71.2 \\
3.1 \pm 0.9 \\
53.8 \pm 11.8 \\
3.2(2.1-4.6) \\
7.1 \pm 1.3 \\
1.3 \pm 0.4 \\
75.8 \pm 3.1 \\
66.8 \pm 6.7 \\
0.1(0.1-3.7) \\
4.7 \pm 0.8 \\
11.5 \pm 0.8 \\
16.0 \pm 1.5 \\
30.9 \pm 3.0 \\
1.0(0.1) \\
1.6(1.2-2.2)\end{array}$ & $\begin{array}{l}\text { NA } \\
303.9 \pm 73.2 \\
3.4 \pm 0.8 \\
54.6 \pm 9.3 \\
3.7(2.5-5.0) \\
6.8 \pm 1.2 \\
1.2 \pm 0.3 \\
76.4 \pm 2.8 \\
66.2 \pm 5.7 \\
0.1(0.1-0.6) \\
4.3 \pm 0.7 \\
11.3 \pm 0.6 \\
15.8 \pm 1.1 \\
29.5 \pm 3.3 \\
1.0(0.1) \\
1.6(1.2-2.2)\end{array}$ & $\begin{array}{l}0.796 \\
0.094 \\
0.623 \\
0.095 \\
0.089 \\
0.071 \\
0.175 \\
0.524 \\
0.363 \\
0.001 \\
0.063 \\
0.287 \\
0.010 \\
0.191 \\
0.955\end{array}$ \\
\hline $\begin{array}{l}\text { Neonatal weight }(\mathrm{g} \text {, mean } \pm \mathrm{sd}) \\
\text { Maternal events }\end{array}$ & $3354.1 \pm 569.7$ & $3320.6 \pm 449.1$ & 0.678 \\
\hline
\end{tabular}




\begin{tabular}{|c|c|c|c|}
\hline $\begin{array}{l}\text { Cesarean delivery }(n, \%) \\
\text { Wound infection after Caesarean delivery }\end{array}$ & $\begin{array}{l}28(56.0 \%) \\
2(4.0 \%)\end{array}$ & $\begin{array}{l}50(37.9 \%) \\
3(2.3 \%)\end{array}$ & $\begin{array}{l}0.027 \\
0.906\end{array}$ \\
\hline $\begin{array}{l}\text { (persons,n,\%) } \\
\text { Thrombotic event (n,\%) }\end{array}$ & $1(2.0 \%)$ & $2(1.5 \%)$ & 0.677 \\
\hline Neonatal events & & & \\
\hline Neonatal malformation $(n, \%)$ & $4(8.0 \%)$ & $2(1.5 \%)$ & 0.084 \\
\hline Intrauterine growth retardation or fetal distress $(n, \%)$ & $4(8.0 \%)$ & $2(1.5 \%)$ & 0.084 \\
\hline Perinatal death $(n, \%)$ & $0(0)$ & $0(0)$ & \\
\hline Still birth $\geq 24$ weeks $(n, \%)$ & $0(0)$ & $0(0)$ & \\
\hline Preterm birth $(n, \%)$ & $11(22.0 \%)$ & $47(35.6 \%)$ & 0.114 \\
\hline Very Preterm birth (n,\%) & $0(0)$ & $9(6.8)$ & 0.132 \\
\hline Macrosomia $(n, \%)$ & $6(12.0 \%)$ & $10(7.6 \%)$ & 0.521 \\
\hline
\end{tabular}

Data were expressed as mean $\pm S D$ (normally distributed) if normally distributed, and median (interquartile range) or $\mathrm{N}(\%)$ if not.

Note: SBP: systolic blood pressure; DBP: diastolic blood pressure; RBC: blood erythrocytes count; WBC: blood leukocyte count; NE: neutrophile granulocyte; DBIL: direct Bilirubin; STB: Serum total bilirubin; IBIL: indirect bilirubin; AST $\square$ aspartate aminotransferarase; ALT: alanine aminotransferarase; LDH: lactate dehydrogenase; ALP: alkaline phosphatase; $\gamma-G G T: \gamma$-glutamyl transpeptadase; FPG:fasting plasma glucose; HbA1c: glycated haemoglobin; UA: plasma uric acid; R: reaction time; K: kinetic time; a-angle: a measure of clot kinetics; MA: maximum amplitude; LY30: the percentage reduction in amplitude 30 min post-MA; FIB: fibrinogen; PT $\square$ prothrombin time; TT $\square$ thrombin time; APTT $\square$ activated partial thromboplastin time; PT-INR $\rrbracket$ international normalized ratio of prothrombin time; DD: D-Dimer.

Table 2 Univariate analyses of CFA parameters

\begin{tabular}{|c|c|c|c|c|c|c|}
\hline & FIB $(\mathrm{g} / \mathrm{L})$ & $\begin{array}{l}P \\
\text { value }\end{array}$ & $\begin{array}{l}\text { APTT } \\
\text { (seconds) }\end{array}$ & $\begin{array}{l}P \\
\text { value }\end{array}$ & LY30 (\%) & $\begin{array}{l}P \\
\text { value }\end{array}$ \\
\hline & $\beta(95 \% \mathrm{Cl})$ & & $\dot{\beta}(95 \% \mathrm{Cl})$ & & $\beta(95 \% \mathrm{Cl})$ & \\
\hline I & $\begin{array}{l}0.39(0.20, \\
0.60)\end{array}$ & 0.001 & $\begin{array}{l}1.40(0.30, \\
2.50)\end{array}$ & 0.010 & $1.30(0.40$ & 0.008 \\
\hline $\begin{array}{l}\text { snal weight gain during } \\
\text { nancy }\end{array}$ & $\begin{array}{l}-0.04(-0.06 \\
-0.02)\end{array}$ & 0.002 & $\begin{array}{l}-0.05(-0.15 \\
0.06)\end{array}$ & 0.408 & $\begin{array}{l}0.01(-0.09 \\
0.11)\end{array}$ & 0.834 \\
\hline slet & $\begin{array}{l}0.00(0.00 \\
0.01)\end{array}$ & 0.034 & $\begin{array}{l}-0.01(-0.02 \\
0.00)\end{array}$ & 0.061 & $\begin{array}{l}-0.00(-0.01, \\
0.01)\end{array}$ & 0.360 \\
\hline & $\begin{array}{l}0.01(0.00 \\
0.01)\end{array}$ & 0.013 & $\begin{array}{l}0.01(-0.02 \\
0.03)\end{array}$ & 0.688 & $\begin{array}{l}0.03(0.01 \\
0.06)\end{array}$ & 0.004 \\
\hline & $\begin{array}{l}0.00(0.00 \\
0.01)\end{array}$ & 0.040 & $\begin{array}{l}0.00(-0.01 \\
0.01)\end{array}$ & 0.581 & $\begin{array}{l}0.01(-0.00 \\
0.02)\end{array}$ & 0.073 \\
\hline & $\begin{array}{l}0.01(0.00 \\
0.01)\end{array}$ & 0.041 & $\begin{array}{l}-0.01(-0.04 \\
0.02)\end{array}$ & 0.549 & $\begin{array}{l}0.02(-0.01 \\
0.04)\end{array}$ & 0.176 \\
\hline & $\begin{array}{l}0.17(0.06, \\
0.29)\end{array}$ & 0.004 & $\begin{array}{l}-0.01(-0.54 \\
0.53)\end{array}$ & 0.982 & $\begin{array}{l}0.02(-0.45 \\
0.50)\end{array}$ & 0.928 \\
\hline ious history of abortion & $\begin{array}{l}-0.34(-0.56, \\
-0.13)\end{array}$ & 0.002 & $\begin{array}{l}0.05(-0.93 \\
1.02)\end{array}$ & 0.922 & $\begin{array}{l}0.30(-0.57 \\
1.17)\end{array}$ & 0.499 \\
\hline $\begin{array}{l}\text { ious history of full-term } \\
\text { s }\end{array}$ & $\begin{array}{l}-0.25(-0.46, \\
-0.03)\end{array}$ & 0.027 & $\begin{array}{l}-0.33(-1.30 \\
0.64)\end{array}$ & 0.506 & $\begin{array}{l}-0.06(-0.93, \\
0.80)\end{array}$ & 0.887 \\
\hline
\end{tabular}

ə are $\beta$ (95\% confidence interval [CI]) and $P$ value 
Table 3: Analysis of associations of GDM with FIB, APTT, and FY30

\begin{tabular}{ccccc}
\hline & Unadjusted $\beta, 95 \% \mathrm{CI}$ & $\boldsymbol{P}$ & ${ }^{\dagger}$ Adjusted $\beta, 95 \% \mathrm{CI}$ & $\boldsymbol{P}$ \\
\hline FIB (g/L) & $0.39(0.16,0.63)$ & 0.001 & $0.38(0.14,0.61)$ & 0.002 \\
APTT (seconds) & $1.40(0.34,2.46)$ & 0.010 & $1.41(0.29,2.53)$ & 0.015 \\
LY30 (\%) & $1.30(0.35,2.24)$ & 0.008 & $1.14(0.15,2.13)$ & 0.026 \\
\hline
\end{tabular}

${ }^{\dagger}$ The adjusted $\beta$ controls for prenatal maternal age, platelet, ALT, ALP, plasma urea nitrogen, and previous history of abortion.

\section{Figures}

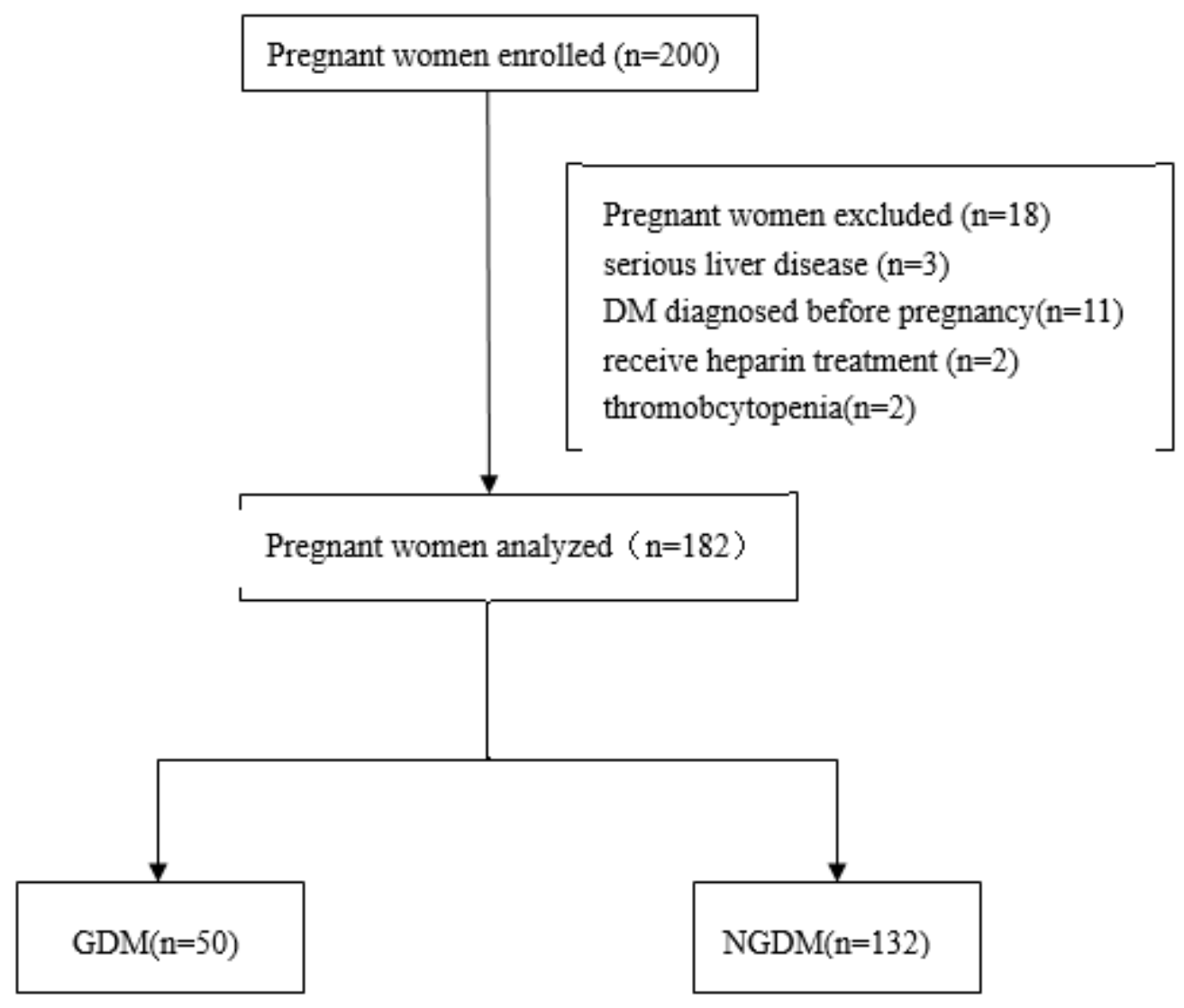

Figure 1

Flowchart of participants selection 


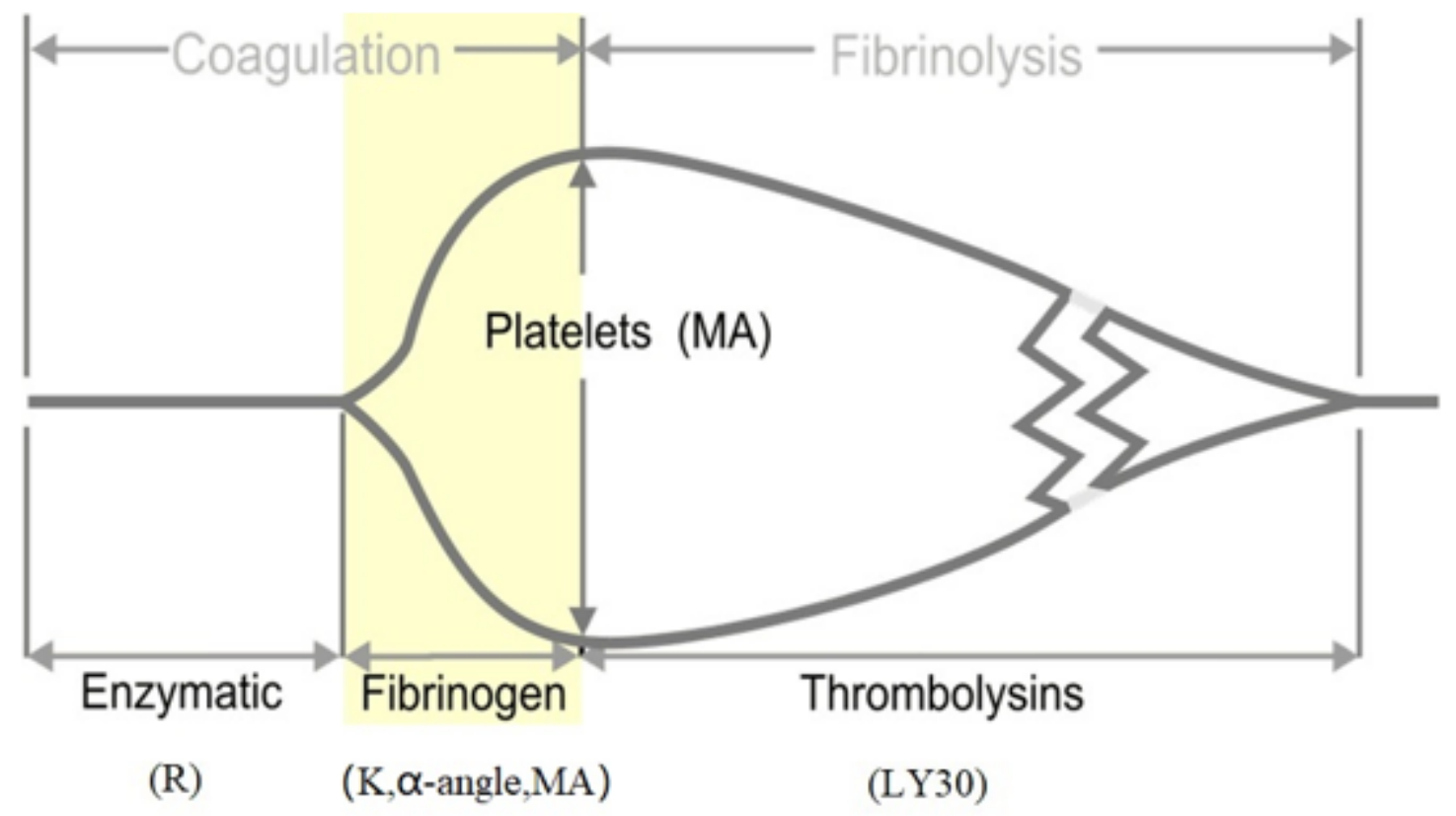

Figure 2

schematic diagram of TEG and the parameters 